\title{
Planos decenais de educação: sistematização do monitoramento e avaliação nos cenários estadual e municipal
}

\section{Decennial education plans: systematization of monitoring and evaluation in the state and municipal scenarios}

\section{Planes decenales de educación: sistematización del monitoreo y evaluación en los escenarios estadales y municipales}

\author{
Elisangela Alves da Silva Scaff ${ }^{1}$ \\ Marli dos Santos de Oliveira ${ }^{2}$
}

DOI: http://dx.doi.org/10.20435/serie-estudos.v23i47.1081

\begin{abstract}
Resumo: O presente texto tem como objetivo identificar as ações concernentes ao monitoramento e à avaliação do Plano Estadual de Educação de Mato Grosso do Sul e do Plano Municipal de Educação de Naviraí, MS. Utiliza-se como metodologia a pesquisa documental, realizada nos sítios do Ministério da Educação, do Conselho Estadual de Educação e do Fórum Estadual de Educação, bem como nos Diários Oficiais do Estado e do Município em análise. Os resultados evidenciam a constituição de comissões para avaliação e monitoramento dos planos tanto em nível estadual quanto municipal, com elaboração do instrumento para levantamento de dados pelo Fórum Estadual de Educação de Mato Grosso do Sul. No cenário nacional, contudo, a conjuntura desenhada a partir das reformas educacionais empreendidas pelo governo federal, desde 2016, aponta para imensos desafios às equipes responsáveis pelo monitoramento e avaliação dos planos educacionais, os quais devem ser considerados para além da dimensão técnica, mas, sobretudo como instrumento político com vistas à garantia de um projeto educacional construído coletivamente pela sociedade brasileira, cujas metas e estratégias primam pela melhoria da qualidade da educação no Brasil.
\end{abstract}

Palavras-chave: planejamento educacional; Plano Nacional de Educação; Plano Estadual de Educação; Plano Municipal de Educação; monitoramento e avaliação.

\footnotetext{
${ }^{1}$ Universidade Federal do Paraná (UFPR), Curitiba, Paraná, Brasil.

${ }^{2}$ Universidade Federal da Grande Dourados (UFGD), Dourados, Mato Grosso do Sul, Brasil.
} 


\begin{abstract}
This article intends to identify actions related to monitoring and evaluation of the State Plan of Education of Mato Grosso do Sul and the Municipal Plan of Education of Naviraí, MS. The methodology used was documentary research in the sites of the Ministry of Education, the State Council of Education and the State Forum of Education, as well as Diario Official of the State and Municipality under analysis. The results show the establishment of commissions for evaluation and monitoring of plans at both the state and municipal level, with elaboration of the instrument for data collection by the State Forum of Education of Mato Grosso do Sul. In the national scenario, however, the scenario drawn from the educational reforms undertaken by the federal government since 2016 points to immense challenges for the teams responsible for monitoring and evaluating educational plans, which should be considered beyond the technical dimension, but above all as a political instrument to guarantee an educational project collectively built by Brazilian society, whose goals and strategies focus on improving the quality of education in Brazil.
\end{abstract}

Keywords: educational planning; National Education Plan; State Education Plan; Municipal Education Plan; monitoring and evaluation.

Resumen: El presente texto tiene como objetivo identificar las acciones concernientes al monitoreo y la evaluación del Plan Estadual de Educación de Mato Grosso do Sul y del Plan Municipal de Educación de Naviraí, MS. Se utiliza como metodología la investigación documental, realizada en los sitios del Ministerio de Educación, del Consejo Estatal de Educación y del Foro Estadual de Educación, así como de Diarios Oficiales del Estado y del Municipio en análisis. Los resultados evidencian la constitución de comisiones para evaluación y monitoreo de los planes tanto a nivel estadual como municipal, con elaboración del instrumento para levantamiento de datos por el Foro Estadual de Educación de Mato Grosso do Sul. En el escenario nacional, sin embargo, la coyuntura diseñada a partir de las reformas educativas emprendidas por el gobierno federal desde 2016, apunta a inmensos retos a los equipos responsables del monitoreo y evaluación de los planes educativos, los cuales deben ser considerados más allá de la dimensión técnica, pero, sobre todo como instrumento político con miras a la garantía de un proyecto educativo Construido colectivamente por la sociedad brasileña, cuyas metas y estrategias priman por la mejora de la calidad de la educación en Brasil.

Palabras clave: planificación educativa; Plan Nacional de Educación; Plan Estadual de Educación; Plan Municipal de Educación; monitoreo y evaluación.

\title{
1 CONSIDERAÇÕES INICIAIS
}

A trajetória dos planos educacionais elaborados no percurso histórico brasileiro revela sua fragilidade frente às oscilações políticas e sociais em seu entorno, o que tem comprometido a efetivação e a até mesmo a aprovação de todos os planos elaborados até a primeira década dos anos 2000. Via de regra, as tentativas de elaboração de planos nacionais de educação no Brasil foram obstruídas por golpes de estado que interromperam a democracia em âmbito nacional, instaurando períodos ditatoriais caracterizados pela centralização do planejamento e restrição de qualquer manifestação de cunho participativo por parte da sociedade civil. 
Planos decenais de educação: sistematização do monitoramento e avaliação nos cenários estadual e municipal

Assim ocorreu na década de 1930, em que a primeira experiência voltada para a elaboração de um Plano Nacional de Educação (PNE) foi interrompida pela ditadura denominada de "Estado Novo". Retomado em 1945, com a abertura democrática do país, outro golpe de estado interrompe o já avançado processo de elaboração do PNE de 1962, dando início ao longo período de ditadura militar que se estendeu de 1964 a 1985 (CURY, 2013; BEISIEGEL, 2016).

A abertura democrática iniciada em 1985 instigou a mobilização dos movimentos sociais filiados ao campo educacional com vistas à elaboração de um novo PNE. A Constituição Federal de 1988, ao outorgar aos municípios brasileiros o status de entes federativos, atribuiu a eles responsabilidade sobre a elaboração de planos que atendam às necessidades da esfera local. Tal princípio, aliado a um projeto democrático assumido pelo Estado brasileiro desde meados dos anos de 1980, traz para a cena os sujeitos integrantes da vida política. Assim, os movimentos de mobilização da sociedade vêm se intensificando nos últimos anos a fim de promover a ampla participação dos sujeitos e das organizações sociais na articulação de políticas de Estado para a educação brasileira.

A participação desses novos sujeitos no processo de construção da política pública implica a reconfiguração do papel do Estado, uma vez que cria elementos para a constituição do conceito de governança local que incorpora, via interações múltiplas, a relação governo e sociedade (GOHN, 2011). Nesse contexto, a arena política local se complexifica, revelando particularidades educacionais, regionais, culturais e econômicas que influenciam na efetivação das políticas nos municípios. As práticas de planejamento educacional em geral, e nos municípios em particular, intensificam-se na primeira década dos anos 2000, sob coordenação da União, a fim de dar organicidade às ações nos diferentes âmbitos.

O primeiro PNE elaborado sob a égide da Constituição Federal de 1988 foi marcado pela ampla participação da sociedade brasileira, por meio de dois Congressos Nacionais de Educação (CONED) e amplos debates realizados por todo o país, sob a coordenação do Fórum Nacional em Defesa da Escola Pública (FNDEP). No entanto o projeto elaborado pela sociedade brasileira não logrou êxito, uma vez que contestava o projeto neoliberal do governo federal em curso. Após longo percurso de debates e enfrentamentos, o documento aprovado e sancionado pela Lei n. 10.172, de 9 de janeiro de 2001 (BRASIL, 2001), restou comprometido diante dos limites orçamentários que impediam a concretização de suas metas. 
Avaliação publicada por Dourado (2010) aponta o descompasso entre o proposto no PNE (2001-2011) e o efetivado na trajetória política brasileira, uma vez que "as prioridades das políticas educacionais adotadas pelos governos, em especial o federal, não tiveram o PNE como indutor central de suas ações político-pedagógicas" (DOURADO, 2010, p. 693). Acrescenta ainda o autor que

[...] a aprovação de planos estaduais e municipais, previstos no PNE como base para a sua organicidade, não se efetivou como política concreta na maior parte dos estados e municípios, e, desse modo, tal processo não contribuiu para o avanço na dinâmica de democratização do planejamento e da gestão da educação no país e para a ratificação do Plano como política de Estado. (DOURADO, 2010, p. 685).

O PNE (2001-2010), embora tenha incumbido estados e municípios de elaborarem seus respectivos planos decenais de educação, não estipulou um prazo para que isso acontecesse, resultando em poucos planos aprovados durante sua vigência. Registre-se ainda que o referido PNE não foi acionado como documento norteador da educação brasileira e teve, consequentemente, poucas metas e estratégias alcançadas.

Dez anos depois, a exigência de aprovação de um novo PNE mais uma vez mobilizou a sociedade civil brasileira, organizada por um projeto nacional, agora coordenado pelo governo federal. Em um processo marcado por tensões de ordem política e econômica, tal projeto foi aprovado pela Lei n. 13.005, de 25 de junho de 2014 (BRASIL, 2014).

O Plano Nacional de Educação (PNE 2014-2024) foi concebido a partir de amplo debate ocorrido nas diversas etapas da Conferência Nacional de Educação (CONAE) nos anos de 2010 e 2014. Composto por diretrizes, metas e estratégias que abrangem todos os níveis, etapas e modalidades de ensino, o PNE visa ampliar o acesso e a melhoria da qualidade da educação nacional com vistas a garantir os direitos constitucionalmente consagrados.

O Artigo 8o da supramencionada lei dispõe que estados, Distrito Federal e os municípios deveriam elaborar ou adequar seus respectivos planos de educação em consonância com o PNE, no prazo de um ano após sua aprovação (BRASIL, 2014). O quadro 1 a seguir aponta a situação dos Planos Estaduais de Educação, com base nos dados pesquisados em junho de 2017, isto é, 3 anos após o prazo estabelecido pelo PNE (2014-2024). 
Planos decenais de educação: sistematização do monitoramento e avaliação nos cenários estadual e municipal

\begin{tabular}{|c|c|c|c|}
\hline Região & Estado & Lei & Aprovação \\
\hline \multirow{7}{*}{ Norte } & Acre & $N^{\circ} 2.965$ & 22/07/2015 \\
\hline & Amazonas & $N^{\circ} 4.183$ & $26 / 06 / 2015$ \\
\hline & Rondônia & $N^{\circ} 3.565$ & $03 / 06 / 2015$ \\
\hline & Roraima & $N^{\circ} 1.008$ & 03/09/2015 \\
\hline & Amapá & $N^{\circ} 1.907$ & $24 / 06 / 2015$ \\
\hline & Pará & $N^{\circ} 8.186$ & $23 / 06 / 2015$ \\
\hline & Tocantins & $N^{\circ} 2.977$ & $08 / 07 / 2015$ \\
\hline \multirow{9}{*}{ Nordeste } & Maranhão & $N^{\circ} 10.099$ & $11 / 06 / 2014$ \\
\hline & Piauí & $N^{\circ} 6.733-$ & $17 / 12 / 2015$ \\
\hline & Ceará & $N^{\circ} 16.025$ & $30 / 05 / 2016$ \\
\hline & Bahia & $N^{\circ} 13.559$ & $11 / 05 / 2016$ \\
\hline & Sergipe & $N^{\circ} 8.025$ & 04/09/2015 \\
\hline & Alagoas & $N^{\circ} 7.795$ & $22 / 01 / 2016$ \\
\hline & Pernambuco & $N^{\circ} 15.533$ & $23 / 06 / 2015$ \\
\hline & Paraíba & $N^{\circ} 10.488$ & $23 / 06 / 2015$ \\
\hline & Rio Grane do Norte & $N^{\circ} 10.044$ & $27 / 01 / 2016$ \\
\hline \multirow{3}{*}{ Centro-Oeste } & Mato Grosso & $N^{\circ} 10.111$ & 06/06/2014 \\
\hline & Mato Grosso do Sul & $N^{\circ} 4.621$ & $22 / 12 / 2014$ \\
\hline & Goiás & $N^{\circ} 18.969$ & $22 / 07 / 2014$ \\
\hline \multirow{4}{*}{ Sudeste } & Minas Gerais & \multicolumn{2}{|c|}{ Com projeto de lei enviado ao Legislativo } \\
\hline & São Paulo & $N^{\circ} 16.279$ & 08/07/2016 \\
\hline & Espírito Santo & $N^{\circ} 10.382$ & $25 / 06 / 2015$ \\
\hline & Rio de Janeiro & \multicolumn{2}{|c|}{ Com documento base elaborado } \\
\hline \multirow{3}{*}{ Sul } & Paraná & $N^{\circ} 18.492$ & $24 / 06 / 2015$ \\
\hline & Santa Catarina & $N^{\circ} 16.794$ & $14 / 12 / 2015$ \\
\hline & Rio Grande do Sul & $N^{\circ} 14.705$ & $25 / 06 / 2015$ \\
\hline
\end{tabular}

Quadro 1 - Situação dos Planos Estaduais de Educação, 2017

Fonte: Elaboração própria com base em PNE em Movimento (2017).

Como se observa, dos 26 estados da federação, apenas dois ainda não aprovaram seus respectivos Planos Estaduais de Educação, ambos da região Sudeste. O estado do Rio de Janeiro está com o documento base elaborado, e o de Minas Gerais, com o projeto de lei enviado ao Legislativo. Embora não seja pretensão deste texto verificar as particularidades desses planos, é importante registrar o avanço do PNE 2014-2024, em comparação com o PNE 2001-2014, cujos Planos Estaduais aprovados limitaram-se a 12 estados da Federação, conforme apontam Sousa e Menezes (2015). 
Com relação aos municípios, a situação dos planos de educação, levantada pelo $\mathrm{MEC} / \mathrm{PNE}^{3}$, aponta que apenas 14 ainda não sancionaram a Lei do Plano Municipal de Educação, sendo que destes nove encontram-se com projeto enviado ao legislativo, um possui lei aprovada, mas ainda não sancionada, dois informam possuir projeto de lei elaborado, um município está na fase de conclusão da consulta pública e um apenas elaborou o documento base (BRASIL, 2014).

No estado de Mato Grosso do Sul, o Plano Estadual de Educação foi aprovado em 2014 e todos os municípios encontram-se com a Lei do Plano Municipal de Educação sancionada, o que remete a um novo desafio, qual seja, o monitoramento e a avaliação desses planos com vistas ao cumprimento das suas respectivas metas e estratégias. Conforme Januzzi (2014),

[...] monitoramento constitui um processo sistemático e contínuo de acompanhamento de uma política, programa ou projeto, baseado em um conjunto restrito - mas significativo e periódico - de informações, que permite uma rápida avaliação situacional e uma identificação de fragilidades na execução, com o objetivo de subsidiar a intervenção oportuna e a correção tempestiva para o atingimento de seus resultados e impactos. (JANUZZI, 2014, p. 32).

Entendido dessa forma, o monitoramento pode ser considerado como uma avaliação em processo (RUA, 2007), que permite o acompanhamento da política de forma a identificar os avanços e fragilidades de sua execução, subsidiando o poder público com dados que possibilitem ajustes e correções a serem aplicados no decorrer do processo, para que seu objetivo final seja alcançado. Com vistas a um processo de monitoramento e avaliação de planos de educação, numa perspectiva de mobilização e participação social, Dourado, Grossi Jr. e Furtado (2016, p. 457-8) consideram que:

a) o monitoramento e a avaliação devem ser compreendidos como processo único; b) a mobilização e a participação da sociedade são condições indispensáveis para garantir transparência e acesso a todas as informações, bem como para contribuir para o efetivo cumprimento das metas e estratégias; c) os gestores da política educacional [...] e os profissionais da educação são lideranças reconhecidas no âmbito do território e, consequentemente, são importantes articuladores de toda ação a ser desenvolvida [...].

\footnotetext{
${ }^{3}$ http://pne.mec.gov.br/planos-de-educacao/situacao-dos-planos-de-educacao
} 
Planos decenais de educação: sistematização do monitoramento e avaliação nos cenários estadual e municipal

No âmbito do planejamento educacional, avaliação e monitoramento constituem-se elementos fundamentais, tendo sido incorporados no Art. 50 da Lei n. 13.005, de 25 de junho de 2014, que aprova o PNE (2014-2024), estabelecendo "A execução do PNE e o cumprimento de suas metas serão objeto de monitoramento contínuo e de avaliações periódicas". Em vista desse cenário, o presente estudo tem como objetivo verificar as ações em curso concernentes ao monitoramento e à avaliação de um plano estadual e um plano municipal de educação, elaborados sob a égide do PNE (2014-2024).

Elege-se para tanto o Plano Estadual de Educação de Mato Grosso do Sul, um dos três primeiros estados a elaborar o PEE (2014-2024), e o Plano Municipal de Educação de Naviraí, sancionado como Lei n. 1.933, de16 de junho de 2015. Utiliza-se como metodologia a pesquisa documental, realizada nos sítios do Ministério da Educação, do Conselho Estadual de Educação e do Fórum Estadual de Educação de Mato Grosso do Sul, bem como Diários Oficiais do Estado e do Município em análise.

Dado o histórico de rupturas que marca a trajetória dos planos educacionais no Brasil, o monitoramento dos PEEs e PMEs adquire ainda maior relevância, especialmente diante do cenário político que sucede à aprovação do PNE (20142024), cujas reformas empreendidas nas políticas públicas sinalizam para retrocessos históricos no campo dos direitos sociais conquistados desde a Constituição Federal de 1988.

\section{MONITORAMENTO E AVALIAÇÃO DO PLANO ESTADUAL DE MATO GROSSO DO SUL (2014-2024)}

O Plano Estadual de Educação de Mato Grosso do Sul ${ }^{4}$ (PEE-MS) foi aprovado pela Lei n. 4.621 de 22 de dezembro de 2014, com vigência para o período de 2014-2024. Alinhado ao PNE (2014-2024), o PEE-MS estabelece diretrizes e compromissos em suas 20 metas e mais de 350 estratégias. A elaboração do referido

\footnotetext{
${ }^{4}$ Cumpre registrar que a organização político-administrativa do MS é constituída pela existência de 79 municípios com seus centros urbanos administrativos e 85 distritos. A organização de seu espaço geográfico para fins de estudos voltados ao planejamento organiza-se em nove regiões, cujos municípios atuam em torno de um polo de liderança regional, com laços de interdependência e inter-relação, quais sejam: Região de Campo Grande, Região da Grande Dourados, Região do Bolsão, Região do Cone Sul, Região do Pantanal, Região Leste, Região Norte, Região Sudoeste e Região Sul-Fronteira (MATO GROSSO DO SUL, 2015).
} 
plano resulta das proposições da II Conferência Estadual de Educação, realizada em 2013, por meio de oficinas e seminários regionais que culminaram, em 2014, na realização do Seminário Estadual de Educação: construindo coletivamente o Plano Estadual de Educação (2014-2024).

Nesse contexto, importa destacar os marcos que antecederam a aprovação do PEE-MS (2014-2024), a saber: a) 10 Plano Estadual de Educação (PEE)- Lei n. 2.791, de 30 de dezembro de 2003, vigente até 2013; b) I Conferência Nacional da Educação Básica, em 2008, que culminou com a promulgação da Emenda Constitucional n. 59/2009; c) I Conferência Estadual de Educação, em 2009, cuja realização de 23 conferências municipais e intermunicipais envolveu cerca de 3.000 participantes; d) I Conferência Nacional de Educação (CONAE) 2010; e) II Conferência Estadual de Educação (CONAE) 2013, por meio da qual o Fórum Estadual de Educação, junto às comissões organizadoras, realizou 79 Conferências Livres e 17 Conferências Intermunicipais de Educação (MATO GROSSO DO SUL, 2014; 2017).

As conferências nacionais e, por consequência, as estaduais e municipais se tornaram a mais importante e abrangente ação participativa do Brasil após a CF/1988, levando à institucionalização da participação da sociedade civil nos processos de elaboração, acompanhamento e avaliação das políticas públicas (AVRITZER, 2012). Para o autor as conferências nacionais impactam o poder legislativo na medida em que impulsionam a atividade do Congresso Nacional e fortalecem a democracia representativa por meio de prática participativa e deliberativa, visto congregarem esforços de mobilização e representação em torno da definição de uma política pública (AVRITZER, 2012).

Considerando-se o caráter dinâmico do planejamento educacional, o processo participativo não se esgota com a aprovação do seu resultado - o Plano - mas se estende durante todo o período de execução, que requer avaliação contínua, de forma a monitorar o alcance das estratégias estabelecidas para a concretização de cada meta. Assim, o PEE-MS estabelece, em seu Art. 3ㅜ, que as metas previstas serão objeto de monitoramento contínuo e de avaliações periódicas realizadas por uma Comissão nomeada pelo chefe do Poder Executivo com a participação das seguintes instâncias: I- Secretaria de Estado de Educação (SED-MS); II- Comissão de Educação da Assembleia Legislativa; III - Conselho Estadual de Educação de Mato Grosso do Sul (CEE-MS); IV - Fórum Estadual de Educação de Mato Grosso do Sul (FEEMS) (MATO GROSSO DO SUL, 2014). 
Planos decenais de educação: sistematização do monitoramento e avaliação nos cenários estadual e municipal

Em cumprimento ao disposto, o governo do estado publicou o Decreto n. 14.199, de 28 de maio de 2015 (MATO GROSSO DO SUL, 2015b), que instituiu a Comissão de Monitoramento e Avaliação do Plano Estadual de Educação de Mato Grosso do Sul (CMAPEE), com a composição de representantes das instâncias mencionadas no Art. 3 do PEE-MS acima citado. Essa composição foi alterada pelo Decreto estadual n. 14.281, de 21 de outubro de 2015, que acrescentou as seguintes instâncias: V- Tribunal de Contas do Estado (TCU); VI- União Nacional dos Dirigentes Municipais de Educação (UNDIME-MS); VII União Nacional dos Conselhos Municipais de Educação (UNCME-MS); VIII- Instituição de Educação Superior (IES) pública; IX- Federação dos Trabalhadores em Educação de Mato Grosso do Sul (FETEMS) e; X- Sindicato dos Estabelecimentos de Ensino de Mato Grosso do Sul (SINPE-MS).

Como se observa, a CMAPEE-MS é composta por 10 instituições governamentais e não governamentais, cujos membros foram designados por ato do titular da Secretaria de Estado de Educação de MS. As competências da CMAPEE-MS, designadas no Art. $3^{\circ}$ do referido decreto, são: I Monitorar e avaliar o cumprimento das metas e das estratégias do Plano Estadual de Educação, no período de sua vigência; II-Adotar as providências necessárias para a execução de suas atividades, tendo em vista a tomada de decisões com base nos resultados de pesquisas científicas (MATO GROSSO DO SUL, 2015).

Ainda no que concerne ao monitoramento do PEE-MS, é importante destacar a estratégia 7.49, que prevê a criação, no âmbito dos fóruns de educação, do Observatório do PEE-MS, para monitorar o cumprimento das metas e estratégias estabelecidas no PEE, mantendo-o atualizado e promovendo a divulgação dos resultados à sociedade (MATO GROSSO DO SUL, 2014). Em atendimento ao disposto, o Fórum Estadual de Educação de Mato Grosso do Sul (FEEMS) criou, em Plenária de junho de 2015, o Observatório do PEE-MS, constituído com um Grupo de Trabalho (GT) do referido fórum.

O fórum de educação configura-se como espaço privilegiado de interlocução entre a sociedade civil e o governo, na medida em que possibilita a ampla participação da sociedade na discussão, na elaboração, no acompanhamento e na avaliação das políticas educacionais. Em Mato Grosso do Sul, a criação do FEEMS se deu pelo Conselho Estadual de Educação em 7 de novembro de 1997, é composto por 70 entidades representantes de diversos segmentos e possui duas 
comissões, ambas de caráter permanente, com planos de trabalho e relatórios específicos.

O Regimento Interno do FEEMS caracteriza-o como: I - órgão do Sistema Estadual de Ensino de Mato Grosso do Sul; II- instância de articulação entre governo e sociedade civil organizada; III- espaço de consulta pública e de articulação horizontal com organismos da sociedade civil identificados com a educação; IV - instância de deliberação de propostas de políticas estaduais de educação; V- instância de monitoramento e avaliação das metas e estratégias do PEE-MS; VI- órgão permanente; e VII- órgão de Estado (MATO GROSSO DO SUL, 2015a). Sobre o Observatório do PEE-MS, o referido documento define:

Art. 27. O Grupo de Trabalho (GT) do Observatório do PEE-MS é responsável pela coleta dos dados pesquisados pelos GTPs sobre o cumprimento das metas e estratégias do Plano Estadual de Educação e pela sua inserção na plataforma do Observatório do PEE-MS.

$\S 1$ 응 Os dados coletados pelo GT deverão ser apresentados para apreciação em Plenária do FEEMS.

$\S 2$ 2ㅇs dados divulgados no Observatório do PEE-MS subsidiarão a Comissão prevista no art. 3ำ da Lei n.o 4.621/2014 e ficarão disponíveis para a consulta de gestores, educadores, pesquisadores e sociedade em geral (MATO GROSSO DO SUL, 2015a, p. 8).

Essas disposições acerca do monitoramento e da avaliação, bem como sobre o Observatório do PEE-MS, foram incluídas no Regimento do FEEMS em 2015, após a aprovação do PEE-MS, cujas demandas resultaram na reorganização dos Grupos de Trabalhos Permanentes (GTPs) do Fórum, conforme ilustra o quadro 2 a seguir: 
Planos decenais de educação: sistematização do monitoramento e avaliação nos cenários estadual e municipal

\begin{tabular}{|c|c|c|}
\hline \multicolumn{3}{|c|}{ Grupos de Trabalho permanentes do FEEMS } \\
\hline \multicolumn{3}{|c|}{ GTP da Educação Básica } \\
\hline \multicolumn{3}{|c|}{ GTP da Educação Superior } \\
\hline \multicolumn{3}{|c|}{ GTP da Educação Profissional e Tecnológica } \\
\hline \multicolumn{3}{|c|}{ GTP da Educação Especial } \\
\hline \multicolumn{3}{|c|}{ GTP da Educação para a diversidade } \\
\hline \multicolumn{3}{|c|}{ GTP Educação a Distância e Tecnologias Educacionais } \\
\hline $\mathrm{N}^{\circ}$ & Subgrupos do Observatório do PEE-MS & Metas \\
\hline 01 & Educação Infantil & 1 \\
\hline 02 & Ensino Fundamental & 2 e 5 \\
\hline 03 & Ensino Médio & 3 \\
\hline 04 & Educação Especial & 4 \\
\hline 05 & Qualidade na Educação & 6 e 7 \\
\hline 06 & Educação para a diversidade & 8 e 9 \\
\hline 07 & Educação Profissional e Tecnológica & 10 e 11 \\
\hline 08 & Valorização do Magistério & $15,16,17$ e 18 \\
\hline 09 & Gestão Democrática & 19 \\
\hline 10 & Financiamento da Educação & 20 \\
\hline 11 & Educação a Distância e Tecnologias Educacionais & Estratégias das metas \\
\hline
\end{tabular}

Quadro 2 - Grupos de Trabalho Permanentes e Subgrupos do Observatório do PEE-MS

Fonte: Elaboração própria com base em Mato Grosso do Sul (2017, p. 10).

Como se observa, a reorganização dos GTPS em subgrupos contemplou todas as metas constantes no PEE-MS. Os elementos definidos para sistematização do processo de monitoramento e avaliação do Plano foram: a) Prazo - Para cumprimento da meta ou estratégia; b) Meta ou estratégia- dispostas no PEE-MS; c) Indicador- sistematização de como a ação será avaliada; d) Variáveis - grandezas estruturais que armazenam dados; e) Operação - o resultado da operação definirá a situação de cumprimento do PEE-MS; f) Local - refere-se ao local que contém os dados ou informações, a exemplo o IBGE, o Censo Escolar, etc.; g) Possíveis problemas e observações - referem-se à coleta de dados de cada variável e o registro de outras informações relevantes ao monitoramento do plano (MATO GROSSO DO SUL, 2017).

Para o preenchimento da Planilha de Sistematização do Monitoramento do PEE-MS, as metas e estratégias do Plano foram distribuídas entre os GTPs do 
Fórum, reorganizados para atender tal demanda. "Esta distribuição obedeceu à natureza de cada GTP, garantindo que a sistematização ocorresse por meio da intervenção de profissionais diretamente relacionados à especificidade de cada meta" (MATO GROSSO DO SUL, 2017, p. 12).

A planilha elaborada para a sistematização foi aprovada pela CMAPEE-MS, e o Grupo de Trabalho do Observatório apresentou esse instrumento à equipe da Rede de Assistência Técnica da Secretaria de Articulação com os Sistemas de Ensino (SASE/MEC), que decidiu adotá-la para o monitoramento de todos os planos municipais de educação do MS, adequando-a às suas especificidades (MATO GROSSO DO SUL, 2017). As metas contidas no quadro 3 exemplificam a forma de construção dos indicadores destinados a monitorar e avaliar o PEE-MS e os planos municipais de educação do estado. 


\begin{tabular}{|c|c|c|c|c|c|c|c|c|c|c|c|}
\hline 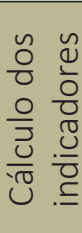 & & 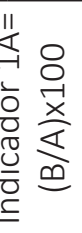 & & 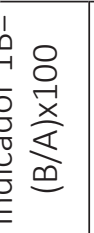 & 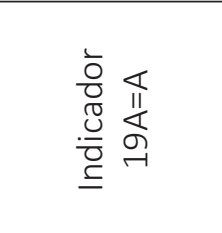 & 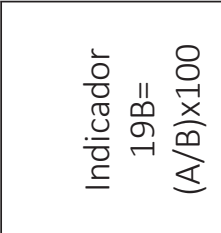 & & 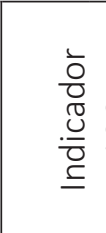 & 㫕 $\frac{\stackrel{8}{0}}{\stackrel{x}{x}}$ & 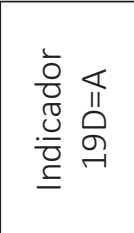 & \\
\hline$\frac{\sqrt{\frac{\pi}{2}}}{\frac{\pi}{10}}$ & 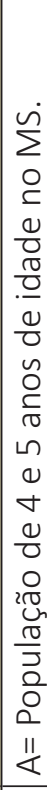 & 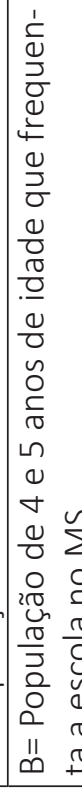 & 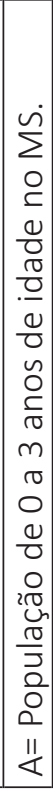 & 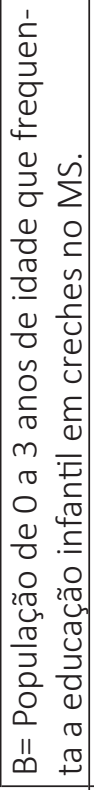 & 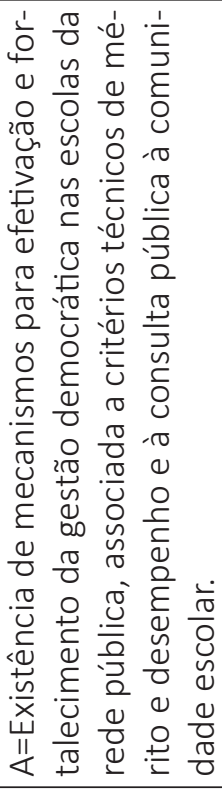 & 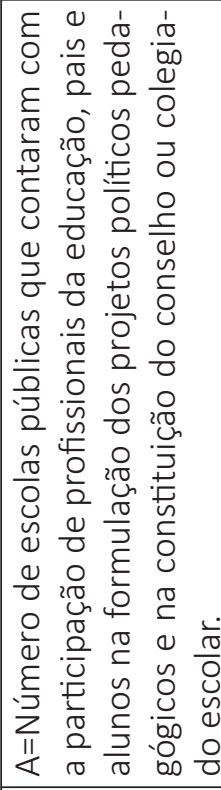 & 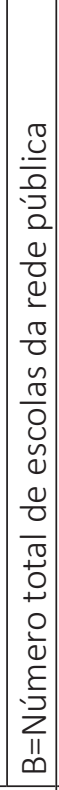 & 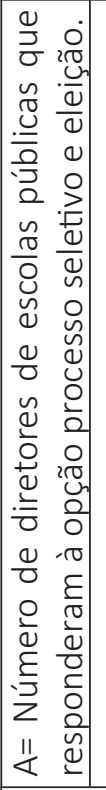 & 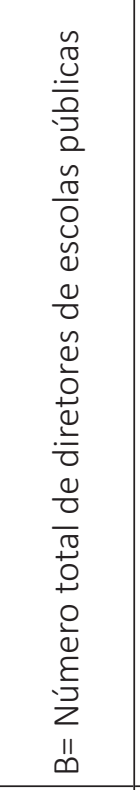 & 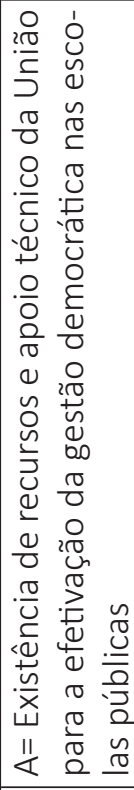 & 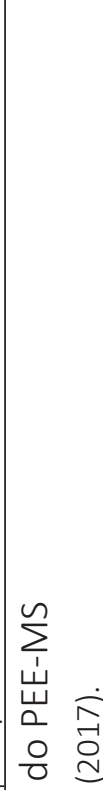 \\
\hline 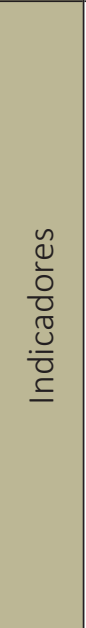 & & $\begin{array}{c}2 \\
0 \\
0 \\
0 \\
0 \\
0\end{array}$ & 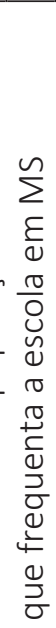 & & 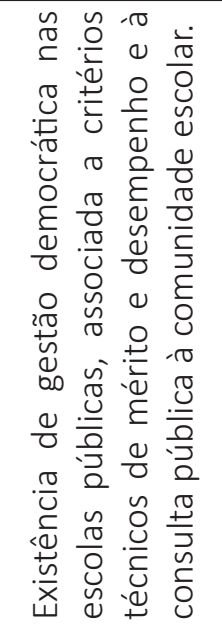 & 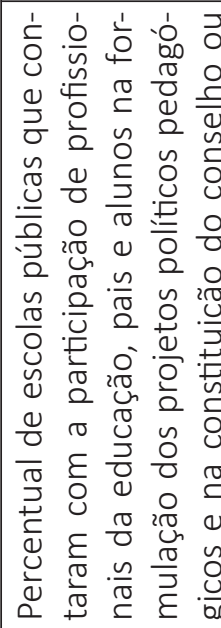 & $\begin{array}{l}\frac{1}{\sigma} \\
0 \\
\breve{y} \\
0 \\
\frac{0}{0} \\
\frac{\sigma}{00} \\
\frac{0}{0} \\
0\end{array}$ & 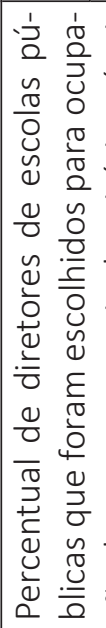 & 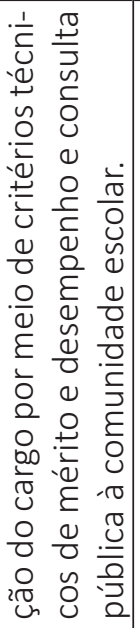 & 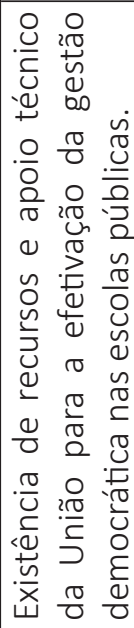 & 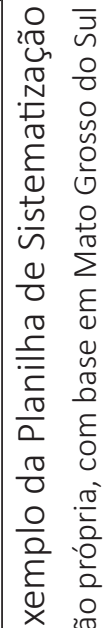 \\
\hline 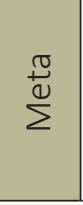 & & & 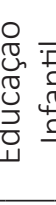 & & & 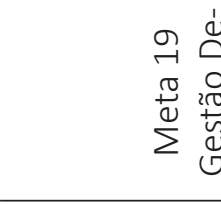 & & & & & 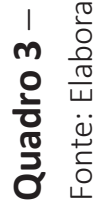 \\
\hline
\end{tabular}


O uso de indicadores tem se intensificado na ultima década, configurando-se como suporte para o planejamento, monitoramento e avaliação das políticas sociais, como indicam Bauer e Sousa (2015, p. 262). Embora a produção de informações aplicáveis às políticas públicas date de meados do século XX, 0 desenvolvimento dos sistemas de informação vem possibilitando o aumento na quantidade de armazenamento de informações, bem como seu compartilhamento inter e intranações (BAUER; SOUSA, 2015,p. 264).

No campo do planejamento educacional, vários sítios da área têm realizado o levantamento, a organização e a divulgação de informações que favorecem o monitoramento e a avaliação dos planos, tanto em âmbito nacional quanto local. Destaque-se entre eles o site do PNE no Ministério da Educação, a Campanha Nacional pelo Direito à Educação; o Observatório do PNE e o Laboratório de Dados Educacionais da Universidade Federal do Paraná ${ }^{5}$.

A despeito do esforço desses grupos, os dados disponibilizados requerem tratamento e análise, de modo a informar o poder público e indicar possibilidades de ação. Como afirmam Bauer e Sousa (2015, p. 264), "A tradução de informações disponíveis em indicadores requer uma análise que articule os dados disponíveis aos propósitos da avaliação", o que exige das equipes locais a familiaridade com metodologias de análise de dados quantitativos e, sobretudo, a capacidade de confrontar dados quantitativos e qualitativos, educacionais e sociais, visando apreender a complexidade dos fenômenos na concretude da realidade local.

\section{MONITORAMENTO E AVALIAÇÃO DOS PLANOS MUNICIPAIS DE EDUCAÇÃO DE MS: O CASO DE NAVIRAÍ}

O PNE (2014-2024) incumbiu os entes federativos subnacionais (estados, Distrito Federal e municípios) de elaborarem ou adequarem seus respectivos planos decenais de educação no prazo de um ano a contar de sua aprovação, fixando o dia 24 de junho de 2015 como data derradeira para que os demais entes elaborassem seus planos. O município de Naviraí ${ }^{6}$ cumpriu essa disposição ao aprovar a Lei n. 1.933 de 16 de junho de 2015.

\footnotetext{
${ }^{5}<$ http://pne.mec.gov.br>; <http://campanha.org.br>; <http://www.observatoriodopne.org.br>; $<$ www.dadoseducacionais.c3sl.ufpr.br>.

${ }^{6}$ Naviraí é um município brasileiro da região Centro-Oeste situado no estado de MS, na Mesorregião do Sudeste de MS e Microrregião de Iguatemi que tem sua gênese em 1951 (NAVIRAÍ, 2014).
} 
Notadamente acerca da formulação do Plano Municipal de Naviraí (PMENAV/2014-2024), Oliveira (2017) aponta limites impostos pela celeridade impressa pela Gerência Municipal de Educação às discussões e deliberações durante o processo de formulação do referido plano, resultando na participação periférica de alguns segmentos.

Apesar dos limites evidenciados por Oliveira (2017), o município de Naviraí sancionou na forma de Lei seu Plano Municipal de Educação, assumindo assim novos compromissos com o governo federal, advindos da necessidade de monitoramento e avaliação do referido plano. Esse processo tem início, oficialmente, com a assinatura do Termo de Adesão à Assistência Técnica para monitoramento e avaliação dos Planos de educação SASE/MEC em 22 de março de 2016.

A Portaria n.15, de 6 de maio de 2016, publicada no Diário Oficial dos Municípios de Mato Grosso do Sul no dia 9 de maio de 2016, dispôs sobre a composição da "Comissão Municipal de Monitoramento e Avaliação do Plano Municipal de Educação de Naviraí/MS - CMMA/PME - Naviraí e da Equipe Técnica da CMMA/ PME-Naviraí" (NAVIRAÍ, 2016). O Art. $2^{\circ}$ dessa Portaria define as instâncias com representatividade por um membro titular, a saber: I- da Gerência Municipal de Educação e Cultura de Naviraí; II - da Secretaria de Estado de Educação; III - da Comissão de Educação do Poder Legislativo; IV - do Conselho Municipal de Educação e V - do Sindicado Municipal dos Trabalhadores em Educação de Naviraí - SIMTED.

A Equipe Técnica, por sua vez, tem sua composição definida no Art. $5^{\circ}:$ I - 5 (cinco) representantes do Núcleo Pedagógico da Gerência Municipal de Educação e Cultura; II-1 (um) representante da Equipe Técnica da Gerência Municipal de Educação e Cultura e; III - 1 (um) representante do Administrativo da Gerência Municipal de Educação e Cultura. No dia 22 de dezembro de 2016 publicou-se a Portaria $N^{\circ} 34$ que dispôs sobre a inclusão do inciso VI no Art. $2^{\circ}$ da Portaria supracitada. Incluiu-se, na ocasião, a representatividade: "VI-do Ministério Público, preferencialmente por meio da Promotoria da Infância e da Juventude".

No ano de 2016, a realização das eleições municipais ocasionou uma desaceleração e, em alguns casos, a interrupção do processo de monitoramento e avaliação dos Planos Municipais de Educação do Mato Grosso do Sul (MATO GROSSO DO SUL, 2017), tal fato torna-se evidente pela inexistência de relatório final referente ao monitoramento de 2016 pelos municípios do estado. O levan- 
tamento da situação dos planos municipais de educação dos 79 municípios de Mato Grosso do Sul é apresentado no quadro 4 a seguir:

\begin{tabular}{|l|c|}
\hline \multicolumn{1}{|c|}{ Situação } & Municípios \\
\hline Com Lei sancionada & 79 \\
\hline Com adesão à assistência técnica & 79 \\
\hline Com instâncias de avaliação designadas na Lei do PME & 79 \\
\hline Com Comissão Coordenadora instituída & 66 \\
\hline Sem Comissão Coordenadora instituída & 13 \\
\hline Agenda de Trabalho elaborada & 50 \\
\hline Ações previstas em execução & 50 \\
\hline
\end{tabular}

Quadro 4- Situação dos Planos Municipais de Educação em Mato Grosso do Sul, 2016

Fonte: Elaboração própria com base em Mato Grosso do Sul (2017).

Naviraí encontra-se no rol dos 66 municípios do estado de Mato Grosso do Sul que possui comissão coordenadora instituída com o objetivo de monitorar e avaliar o seu respectivo plano, todavia as mudanças políticas advindas com as eleições de 2016 ocasionaram alterações na comissão constituída no município, oficializada por meio do Decreto n. 43 de 29 de março de 2017, publicado no Diário Oficial dos municípios do MS, que revogou a Portaria n.15 e n. 34.

Tal Decreto dispõe sobre a nomeação da Comissão Municipal de Monitoramento e Avaliação e Equipe Técnica do PME Naviraí, alterando sua composição, que passou a contemplar das seguintes instâncias: I-Gerente do Núcleo de Recursos de investimentos para a educação; II - Coordenara pedagógica do ensino fundamental - anos iniciais da Gerencia municipal de Educação e cultura; III - Diretora da educação infantil da rede municipal de ensino; IV - Diretora da educação infantil da rede municipal de ensino; $V$-Diretora do ensino fundamental da rede municipal de ensino; $\mathrm{VI}$ - Diretora do ensino fundamental da rede municipal de ensino; VII Coordenadora Pedagógica da educação infantil da rede municipal de ensino; VIII - Professora da educação infantil da rede municipal de ensino; IX-Professora da educação infantil da rede municipal de ensino; $X$ - Professora do ensino fundamental das redes municipal e estadual de ensino; XI - Assistente de administração escolar da Gerencia municipal de educação e cultura e; XII Assistente de administração escolar da rede municipal de ensino. 
Planos decenais de educação: sistematização do monitoramento e avaliação nos cenários estadual e municipal

Nota-se a inclusão de professores e diretores da rede municipal e estadual de ensino, diferentemente do previsto na portaria anterior, cuja composição limitava-se aos funcionários lotados na Gerência Municipal de Educação. Mais do que informações sobre o curso legal do processo de monitoramento, essas informações acerca da composição da Comissão e Equipe Técnica possibilitam apreender, mesmo que de forma inicial, a dinâmica subjacente ao processo de implementação dos planos municipais de educação, sujeitos às mudanças e instabilidades políticas locais.

O monitoramento e a avaliação dos planos decenais de educação exigem um esforço teórico-metodológico na medida em que requerem dos sujeitos envolvidos capacidade técnica e constante reflexão acerca das metas e estratégias contidas no plano, em vista do objetivo final a que se destina. Dessa forma, entende-se, em conformidade com Dourado, Grossi Junior e Furtado (2016), que monitorar e avaliar são partes constantes de um único processo cujas etapas, embora distintas e complementares, não se realizam de modo isolado.

[...] Trata-se de processo complexo que irá requerer mobilização permanente da sociedade civil e política e, especialmente, dos atores definidos nos planos como responsáveis pelo monitoramento e pela avaliação. Em outras palavras, a aprovação dos planos e sua materialização não se efetivam de maneira linear; são dois momentos articulados cuja convergência demandará ações efetivas em direção ao cumprimento das metas e estratégias e a garantia dos planos como epicentro às políticas educacionais brasileiras no âmbito nacional, estadual, municipal e local. (DOURADO; GROSSI JUNIOR; FURTADO, 2016, p. 459).

O envolvimento de novos sujeitos no monitoramento e avaliação do PME, muitos dos quais sequer participaram do processo de formulação deste, implica, indubitavelmente, a retomada das diretrizes e finalidades a que esse plano se propõe, com vistas a contribuir para a efetivação de um projeto nacional de educação, expresso no PNE. Tal projeto, no entanto, tem sofrido revezes desde a efetivação, em 2016, do golpe legislativo-judiciário-midiático (AMARAL, 2017), que resultou na deposição da Presidenta eleita Dilma Rousseff, momento no qual o governo brasileiro passou a empreender reformas que sinalizam para um substantivo retrocesso no que se refere às políticas sociais e à democratização das relações de poder (CARTA DE SÃO LUIZ DO MARANHÃO, 2017), com recuos no que se refere à legislação educacional, retirada de direitos trabalhistas, criminalização do pensamento crítico, além de cortes financeiros nas políticas sociais, 
com vistas a criar condições para a sustentação da dinâmica da acumulação de capital nos próximos vinte anos, como discute Pochmann (2017).

Em dissenso com o PNE (2014-2024), o governo federal apresenta a Medida Provisória 746 de 22 de setembro 2016, que, ao instituir a "Reforma do Ensino Médio", despreza as metas e estratégias estabelecidas no referido plano. Nesse mesmo ano, ocorre a substituição de membros do Conselho Nacional da Educação (CNE), legitimamente indicados por entidades representativas da área, por membros representativos do mercado educacional. Processo semelhante foi empreendido contra o Fórum Nacional de Educação (FNE) em 2017, resultando na renúncia coletiva de vinte entidades integrantes do Fórum e criação, por essas mesmas entidades, do Fórum Nacional Popular de Educação (FNPE).

A mais grave ameaça à concretização das metas e estratégias do PNE (20142024), no entanto, se expressa pela Emenda Constitucional n. 95, aprovada em 13 de dezembro de 2016, que institui novo regime fiscal, com rigorosas limitações orçamentárias às políticas sociais pelos próximos 20 anos, o que é considerado por Amaral (2016) como a morte do PNE, vistas as reduções fiscais que ela implica, as quais inviabilizam completamente a meta 20 , que trata da ampliação do investimento público em educação, com vistas a atingir o patamar de $10 \%$ do Produto Interno Bruto (PIB) até 2024.

Nesse cenário involutivo, a avaliação e o monitoramento dos planos educacionais parecem perder o sentido, uma vez que o alcance das metas possui relação direta com o aporte financeiro do governo federal, considerando-se que mais de 70\% dos municípios brasileiros dependem de recursos da União para a efetivação das políticas sociais. Nesse sentido, defende-se que o monitoramento dos planos, para além de uma avaliação de política, se configure como uma "avaliação política", como definem Figueiredo e Figueiredo (1986, p. 108):

[...] por avaliação política entendemos a análise e elucidação do critério ou critérios que fundamentam determinada política: as razões que a tornam preferivel a qualquer outra. Mais uma vez, porém, recorremos a Brian Barry para lembrar que estas razões têm que ser relevantes, ou seja, devem estar referidas a princípios cuja realização irá, presumivelmente, contribuir para uma desejável quantidade e distribuição de bem-estar. (Grifos nossos).

A "avaliação política", para os autores, precede a "avaliação de política" e consiste em atribuir valor, contemplando os princípios que a fundamentam, 
bem como as consequências de sua implantação ou possível modificação em seu conteúdo (FIGUEIREDO; FIGUEIREDO, 1986, p. 108 e 125). Dessa forma, a avaliação dos planos estaduais e municipais de educação não pode perder de vista os princípios educacionais que fundamentam o PNE, lei que expressa um projeto nacional de educação construído coletivamente por diversos segmentos da sociedade brasileira.

\section{CONSIDERAÇÕES FINAIS}

Decorridos três anos desde a aprovação do Plano Nacional de Educação (2014-2024), e dois anos desde a publicação das leis que aprovam o PEE-MS (2014-2024) e o PME-NAV (2015-2025), a análise do cenário atual em que se encontram os planos decenais de educação aponta para imensos desafios às equipes responsáveis pelo seu monitoramento e avaliação.

Tais desafios, que já se mostravam laboriosos no plano técnico, evidenciam-se ainda mais hostis no campo político, diante das reformas educacionais empreendidas pelo governo federal desde 2016, portanto sob a vigência do PNE (2014-2024), mas que desconsideram totalmente suas metas e estratégias. A conjuntura desenhada a partir de então aponta para recuos históricos de grande magnitude, que remetem aos primeiros Planos de Educação elaborados no país, sufocados pelo cenário político autoritário que atribuiu ao planejamento um caráter técnico-burocrático, voltado para interesses econômicos.

Nesse contexto, importa retomar o Artigo 5o da Lei n. 13.005/2014, que aprova o PNE (2014-2024), estabelecendo a necessidade de monitoramento contínuo e avaliações periódicas do plano. Incorporado ao PEE-MS e ao PMENAV, o monitoramento e a avaliação dos planos educacionais em nível local são considerados aqui para além de sua dimensão técnica, mas, sobretudo, como instrumento político com vistas à garantia de um projeto político-educativo nacional, escolhido pelos milhares de delegados e representantes que atuaram na sua elaboração, referendado pelos poderes legislativo e executivo na forma de Lei, o que impõe ao poder público a responsabilidade pela garantia das condições necessárias à sua efetivação. 


\section{REFERÊNCIAS}

AMARAL, Nelson Cardoso. O "novo" ensino médio e o PNE: haverá recursos para essa política? Revista Retratos da Escola, Brasília, v. 11, n. 20, p. 91-108, jan./jun. 2017. Disponível em: <http://retratosdaescola.emnuvens.com.br/rde/article/view/759>. Acesso em: 31 out. 2017.

. PEC 241: a "morte" do PNE (2014-2024) e o poder de diminuição dos recursos educacionais. Revista Brasileira de Política e Administração da Educação, Goiânia, v. 32, n. 3, p. 653-73, set./dez. 2016.

AVRITZER, Leonardo. Conferências nacionais: ampliando e redefinindo os padrões de participação social no Brasil. Rio de Janeiro: IPEA, 2012.

BAUER, Adriana; SOUSA, Sandra Zakia L. de. Indicadores para avaliação de programas educacionais: desafios metodológicos. Ensaio: Avaliação e Políticas Públicas em Educação, Rio de Janeiro, v. 23, n. 86, p. 259-84, jan./mar. 2015.

BEISIEGEL, Celso de Rui. O Plano Nacional de Educação. Cadernos de Pesquisa, n. 106, p. 217-31, mar. 1999. Disponível em: <http://www.scielo.br/pdf/cp/n106/n106a10.pdf>. Acesso em: 16 maio 2016.

BRASIL. Casa Civil. Lei n. 13.005, de 25 de julho de 2014. Aprova o Plano Nacional de Educação - PNE e da outras providências. Disponível em: <http://www.planalto.gov.br/ ccivil_03/_Ato2011-2014/2014/Lei/L13005.htm>. Acesso em: 26 jun. 2017.

. Casa Civil. Lei n. 10.172, de 9 de janeiro de 2001. Aprova o Plano Nacional de Educação e dá outras providências. Disponível em: <http://www.planalto.gov.br/ccivil_03/ leis/leis_2001/l10172.htm>. Acesso em: 26 jun. 2017.

CARTA DE SÃO LUIZ DO MARANHÃO. Democracia em risco: a pesquisa e a pós-graduação em contexto de resistência. São Luiz, MA: ANPED, out. 2017.

CURY, Carlos Roberto Jamil. O Plano Nacional de Educação de 1936/1937. In: CONGRESSO BRASILEIRO DE HISTORIA DA EDUCAÇÃO, 7. Cuiabá, MT. Anais... Cuiabá, MT, 20 a 23 de maio de 2013.

DOURADO, Luiz Fernandes; GROSSI JÚNIOR, Geraldo; FURTADO, Roberval Angelo. Monitoramento e avaliação dos planos de educação: breves contribuições. Revista Brasileira de Política e Administração da Educação, v. 32, n. 2, p. 449-61 maio/ago. 2016.

DOURADO, Luiz Fernandes. Avaliação do Plano Nacional de Educação 2001-2009: questões estruturais e conjunturais de uma política. Educação e Sociedade, Campinas, SP, v. 31, n. 112, p. 675-705, jul./set. 2010. Disponível em: <http://www.scielo.br/pdf/es/ v31n112/03>. Acesso em: 21 jan. 2016. 
Planos decenais de educação: sistematização do monitoramento e avaliação nos cenários estadual e municipal

FIGUEIREDO, Marcus Faria; FIGUEIREDO, Argelina Maria Cheibub. Avaliação política e avaliação de políticas: um quadro de referência teórica. Análise \& Conjuntura, Belo Horizonte, , v. 1, n. 3, p. 108-29, set./dez. 1986.

GOHN, Maria da Glória. Conselhos gestores e participação sociopolítica. 4. ed. São Paulo: Cortez, 2011.

JANNUZZI, Paulo de Martino. Avaliação de programas sociais: conceitos e referenciais de quem a realiza. Estudos em Avaliação Educacional, São Paulo, v. 25, n. 58, p. 22-42, maio/ago. 2014.

MATO GROSSO DO SUL. Fórum Estadual de Educação. $1^{\circ}$ Relatório de monitoramento e avaliação do Plano Estadual de Educação: sistematização das metas e estratégias. 2017. Disponível em: <https://docs.google.com/viewer?a=v\&pid=sites\&srcid=ZGVmYXVsdGRv bWFpbnxjb2F2bW9wZWVtc3xneDpmOTVjZGNmOTg0ZTJiZWQ>. Acesso em: 7 jul. 2017.

. Fórum Estadual de Educação. Regimento Interno. 2015a. Disponível em: <https:// docs.google.com/viewer?a=v\&pid=sites\&srcid=ZGVmYXVsdGRvbWFpbnxmb3J1bWVkd WNtc3xneDozNjgyMjRINjQ3OWUxMzQ0>. Acesso em: 7 jul. 2017.

. Governo do Estado de. Lei n. 14.199 de 28 de maio de 2015b. Campo Grande, MS: Diário Oficial do Estado de Mato Grosso do Sul, n. 8430, de 29 de maio de 2015b, p. 2. Disponível em: <https://www.jusbrasil.com.br/diarios/92938785/doems-normal-29-05-2015-pg-2>. Acesso em 23 fev. 2017.

. Governo do Estado de. Lei n. 4.621 de 22 de dezembro de 2014. Aprova o Plano Estadual de Educação de Mato Grosso do Sul, e dá outras providências. Disponível em: <http://www.sed.ms.gov.br/wp-content/uploads/sites/67/2015/05/Plano-Estadual-deEduca\%C3\%A7\%C3\%A3o-MS.pdf>. Acesso em: 23 fev. 2017.

NAVIRAÍ. Portaria n. 15 de 6 de maio de 2016. Dispõe sobre a composição da Comissão Municipal de Monitoramento e Avaliação do Plano Municipal de Educação de Naviraí/ MS - CMMA/PME - Naviraí e da Equipe Técnica da CMMA/PME- Naviraí e da outras providências. 2016.

. Lei n. 1.933 de 16 de junho de 2015. Aprova o Plano Municipal de Educação de Naviraí-MS e dá outras providências. Naviraí, MS, 2015.

. Planejamento orçamentário. Anexo II- Descrição dos Programas Governamentais/

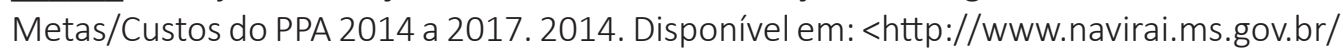
media/W1siZilsImFuZXhvcy8yMDE1LzA1LzA3LzE5XzEwXzA2Xzg2MDk5MDM1OS9SRV NVTU8gTUVUQVMg RSBDVVNUT1Mg LSBQUEEu cGRmIl1d?sha=d46d5c89e726ef50>. Acesso em: 23 fev. 2016.

OLIVEIRA, Marli dos Santos de. Do Plano Nacional aos Planos Municipais de Educação: estudo do município de Naviraí-MS. 2017. Dissertação (Mestrado em Educação) - 
Universidade Federal da Grande Dourados (UFGD), Dourados, MS, 2017. Disponível em: $<$ http://files.ufgd.edu.br/arquivos/arquivos/78/MESTRADO-DOUTORADO-EDUCACAO/ MARLI\%20DOS\%20SANTOS\%20DE\%20OLIVEIRA.pdf>. Acesso em: 10 jun. 2017.

PNE EM MOVIMENTO. Situação dos Planos de Educação. 2017. Disponível em: <http:// pne.mec.gov.br/planos-de-educacao/situacao-dos-planos-de-educacao >. Acesso em: 17 abr. 2017.

POCHMANN, Marcio. Estado e capitalismo no Brasil: a inflexão atual no padrão das políticas públicas do ciclo político da nova república. Educação e Sociedade, Campinas, SP, v. 38, n. 139, p. 309-30, abr./jun. 2017.

RUA, Maria das Graças. Análise de políticas públicas: conceitos básicos. 2007. (Mimeo). SOUSA, Donaldo Bello de; MENEZES, Janaína Specht da Silva. Elaboração e aprovação de planos de educação no Brasil: do nacional ao local. Ensaio: Avaliação e Política Pública, Rio de Janeiro, v. 23, n. 89, p. 901-36, out./dez. 2015.

\section{Sobre as autoras:}

Elisangela Alves da Silva Scaff: Professora do Departamento de Planejamento e Administração Escolar da Universidade Federal do Paraná (UFPR). E-mail: elis-scaff@hotmail.com

Marli dos Santos de Oliveira: Mestre em Educação pela Universidade Federal da Grande Dourados. Doutoranda pela Universidade Federal de Mato Grosso do Sul (UFMS).E-mail: marli.oliveiras@hotmail.com

\section{Recebido em julho de 2017 \\ Aprovado em novembro de 2017}

